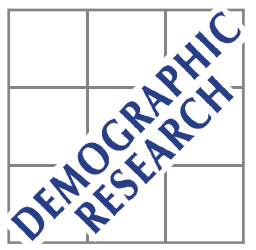

Demographic Research a free, expedited, online journal

of peer-reviewed research and commentary in the population sciences published by the Max Planck Institute for Demographic Research

Konrad-Zuse Str. 1, D-18057 Rostock · GERMANY

www.demographic-research.org

DEMOGRAPHIC RESEARCH

VOLUME 18, ARTICLE 2, PAGES 27-58

PUBLISHED 07 MARCH 2008

http://www.demographic-research.org/Volumes/Vol18/2/

DOI: 10.4054/DemRes.2008.18.2

Research Article

Recent fertility decline in Eritrea:

Is it a conflict-led transition?

\title{
Gebremariam Woldemicael
}

(C) 2008 Woldemicael.

This open-access work is published under the terms of the Creative Commons Attribution NonCommercial License 2.0 Germany, which permits use, reproduction \& distribution in any medium for non-commercial purposes, provided the original author(s) and source are given credit.

See http:// creativecommons.org/licenses/by-nc/2.0/de/ 


\section{Table of Contents}

$\begin{array}{llr}1 & \text { Introduction } & 28\end{array}$

$2 \quad$ Theoretical background 30

$3 \quad$ Data and method 32

$4 \quad$ Description of variables 33

$5 \quad$ Background to Eritrea $\quad 34$

$6 \quad$ Fertility development 37

6.1 Timing of the fertility decline: Trend analysis for 1990-2001 37

6.2 Multivariate analysis 40

$\begin{array}{lll}7 & \text { Discussion and conclusion } & 47\end{array}$

8 Acknowledgements $\quad 50$

$\begin{array}{ll}\text { References } & 51\end{array}$

Annex 56 


\title{
Recent fertility decline in Eritrea: Is it a conflict-led transition?
}

\author{
Gebremariam Woldemicael ${ }^{1}$
}

\begin{abstract}
During a period of military conflict towards the end of the 1990s, Eritrea experienced a remarkable decline in fertility. This decline has been a concern to many Eritreans. An important issue of concern has been whether the decline is driven primarily by the recent border conflict with Ethiopia or by changes in other factors including delay in age at marriage, improvements in child survival and the socio-cultural changes that predated the conflict. Using retrospective event histories from the 1995 and 2002 Eritrea Demographic and Health Surveys (EDHS), this study provides an in-depth exploration of recent fertility change in Eritrea. The findings illustrate that although marriage delay might have played a role in the decline of first births, a decline in fertility within marriage - partly due to cessation of childbearing after families reach their desired family size - is the major contributor to the overall decline. Even though we cannot conclude that the overall fertility decline primarily is the outcome of the conflict, there is evidence that it has contributed substantially to the decline, particularly for first birth fertility. The implications of these findings for theories about fertility change in times of military conflict is that crises may not be likely to initiate a sustainable overall fertility transition, but can still prompt short-term fertility changes among certain social groups or modify an ongoing decline.
\end{abstract}

\footnotetext{
${ }^{1}$ Associate Professor of Demography, University of Asmara. Email: gebre_wm@yahoo.com. Currently a research fellow at Stockholm University, Sociology Department/Demography Unit, SE-106 91 Stockholm, Sweden. Email: gebremariam.woldemicael@ sociology.su.se
} 


\section{Introduction}

Although Eritrea is one of the countries that have witnessed a steady decline in fertility during a military conflict, there is very little evidence that describes how fertility declined so rapidly in a country that apparently meets few of the standard preconditions for fertility transition including significant socio-economic progress, major declines in child mortality, and substantial changes in the status of women. Some progress was made in the realms of education, health care services and agriculture after independence in 1991, particularly between 1992 and 1998, but after this period, Eritrea experienced severe economic declines, internal displacement, and military mobilization as a result of the 1998-2000 border conflict with Ethiopia (GSE and UNICEF, 2001). The records from the EDHS surveys show that Eritrea's infant and child mortality has rapidly and consistently declined since the mid-1990s (NSEO and ORC Macro Inc., 1997, 2003). In terms of women's status, like in most other sub-Saharan African countries, men's dominance and women's dependency on men still exists in Eritrea, particularly in the rural societies, even though some improvements have been made since the struggle for independence (this is discussed in the background section). Regarding the proximate determinants of fertility, Bongaarts and Potter (1983) argue that an increase in contraceptive use and in induced abortion, a relatively late age at marriage as well as long periods of post-partum sexual abstinence and postpartum ammenorrhoea can substantially reduce fertility from its natural maximum. In Eritrea, although contraceptive use is very low and has barely increased since 1995, and duration of postpartum amenorrhoea has remained almost constant since that time, there are indications of recent delays in age at first marriage and increased proportions of nevermarried women at ages 15-49 (NSEO \& ORC Macro Inc, 1997, 2003). In addition, the proportion of married women currently residing with their husband has declined significantly between 1995 and 2002, particularly among younger women (see Table 1). Thus, the decline in fertility can be related to one or more of the proximate variables (Bongaarts et al., 1984) that have changed in recent years, while background variables such as women's educational attainment, urbanization, etc., may have affected fertility by modifying these proximate determinants.

Today, despite the uncertainties that surround the nature and causes of changes in Eritrea's fertility, no comprehensive evidence is available, with the exception of one article on the role of conflict in the rapid fertility decline in Eritrea and its prospects for the future by Blanc (2004) and the reports of the 1995 and 2002 EDHS surveys (NSEO and ORC Macro Inc., 1997, 2003). Blanc's study reveals a TFR decline from 7.1 in 1997/98 to 4.4 in 2000/01, while the EDHS survey shows a TFR decline from 6.1 to 4.8 between 1995 and 2002. Blanc (2004) applied Bongaarts's Proximate Determinants Model (Bongaarts, 1978) to the 2002 EDHS data to examine the relative contribution of 
each proximate determinant to the decline and used TFR to assess the trend in fertility. However, although TFR is an appropriate aggregate measure of fertility that controls for age composition and is useful to compare populations with different age structures, it is not robust to discern whether fertility change can be attributed to changing reproductive pattern at low or high parities (Njogu and Martin, 1991) or to trace changes in fertility behaviour by various socio-demographic characteristics (Luther and Pejaranoda, 1991). Blanc (2004) concluded that the recent fertility decline is mainly an outcome of the border conflict mediated by a reduction in the proportion of women exposed to the risk of pregnancy as a consequence of delayed age at marriage and spousal separation. Whether such impacts would be evident when other more specific factors including parity, spacing of births, and other fertility behaviours are investigated using a multivariate model that controls for various socio-demographic determinants of fertility is still unclear.

In this study, a more comprehensive analysis is made using both trend analyses of TFR and age- and parity-specific fertility rates as well as by applying multivariate regression techniques to our childbearing data. The main purpose for estimating multivariate regression models is to see how trends are related to the included sociodemographic factors and to find out the relative effect and statistical significance of the various explanatory variables in childbearing behaviour. Evidently, although trend analyses of TFR and age- and parity-specific fertility rates are important to give us some ideas about the decline in aggregated fertility by period, they have limitations in that they cannot account for compositional changes among women at childbearing ages or provide information on the relative effects and significance of included variables (i.e., age, parity, socio-economic characteristics, calendar year). The advantages of multivariate regression techniques in fertility and family-demographic trend analyses have been demonstrated in studies for other countries than Eritrea (e.g., Hoem, 1991, 1993; Andersson, 1999a,b; Yavuz, 2006). Thus, failure to take into account the different socio-demographic factors that affect fertility may obscure our understanding of the onset of the decline and the factors that have contributed to it. The timing of fertility decline in Eritrea and its underlying causes are still unresolved issues with many doubts particularly about the effect of the border conflict. In this study, we focus on the analysis of fertility change during the most recent past and do not attempt to cover the pre-independence period. Due to the absence of survey data or any systematic records for the 1980s, we are unable to perform any detailed analyses of the effects of war and other factors on fertility for the period before 1990 . 


\section{Theoretical background}

Several classical demonstrations of demographic transition show the following factors as essential precursors of the trend toward low fertility: the changing structural conditions that alter the costs and benefits of children in the course of socio-economic development, the weakening of normative control as societies are more educated, empowerment of individuals to make their own choices, often for smaller families, and declines in child mortality (see for e.g., Bulatao and Casterline, 2001; Cleland, 2001). In recent years, these explanations are supported or substantiated by another set of explanations that centre on the spread of positive attitudes toward controlled fertility and family planning (Basu and Amin, 2000). These attitudes may build up through a process of diffusion of ideas among people in which individuals' decisions are influenced by the knowledge and behaviour of others including family, relatives, peer groups, elites, etc. with whom they come in contact (Montgomery and Casterline, 1998).

However, empirical evidence on the declines in fertility in the contemporary world has not always been consistent with the above explanations. Other factors, for instance, military conflict, famine, and economic downturn can lead to low aspirations and crisisled fertility transitions (Avogo and Agadjanian, 2007; Hill, 2004; Lindstrom and Berhanu, 1999; Lesthaeghe, 1989; Busza and Lush, 1999; McGinn, 2000).

The proponents of crisis-led fertility decline suggest different pathways through which military conflict can affect fertility. One of the mechanisms is unintentional limiting of births due to social and economic disruptions directly caused by the fighting itself and displacement of people as well as due to temporary separation of couples (Lindstrom and Berhanu, 1999; Hill, 2004), all of which lead to limited exposure to pregnancy and low desire for children. In addition, the number of births may be low during crisis periods as the number of still births, spontaneous and voluntary abortions increase due to deterioration of health services and the nutritional status of pregnant mothers (Palloni et al., 1996; Holck and Cates, 1982). During war periods, the reproductive health problems faced by women are massive and include psychological stress, frustration, despair, weakness, and impairment (Chaudhury et al., 2003). Traumatic experience and psychological stress associated with declines in the reproductive health status are likely to reduce fecundity and frequency of intercourse. Moreover, outbreak of war can lead to conscious adjustments in fertility behaviour because couples are more likely to opt for avoiding births during the time of trouble (CEPED, 1998). For instance, during war periods, family income declines and the support from extended families erode, prices of food and other commodities rises because of destruction of resources or their diversion to non-productive ends, famine and epidemics become widespread (Eloundou-Enyege et al., 2000; Boserup, 1985). 
Such economic hardship may increase couple's awareness of the costs associated with each additional child and the benefits of having fewer children (Rutenberg and Diamond, 1993).

Despite, the above explanations for the support of crisis-driven fertility decline, the empirical record is limited and inconsistent (Agadjanian and Ndola, 2002). For instance, evidence from Angola's experience of conflict for extended period of time shows a wartime drop and a post-war rebound in fertility (Hill, 2004). Similarly, other studies (e.g. Lee, 1997; Palloni et al., 1996) found evidence of crisis induced fertility declines and post-war fertility rebounds. In a recent study on the fertility response to crises in Ethiopia during the 1970s and 1980s - periods marked by social and political upheavals, large population movements, civil war, famine and economic hardship Lindstrom and Berhanu (1999) found mixed evidence of the effects of war and economic crisis on fertility. They noted that fertility in the 1970s remained high and relatively stable, though marked by periodic declines and rebounds in response to specific political and economic events. In 1982, however, fertility began a gradual decline, which appears to have been sustained into the 1990s, when stability returned to the country. The authors attribute this decline to the ongoing civil war and economic decline after 1982.

On the other hand, counter arguments of crisis-led fertility decline suggest that the fertility response may move in the opposite direction. That is, the number of births could increase as a result of crisis. For example, the eight-year war with Iraq (1980-88) created a pronatalist atmosphere among Iranian couples by which they were encouraged to have more children to replace those whose loss they were anticipating, and high fertility and population growth was considered as a matter of comparative advantage by the government of Iran (Abbasi-Shavazi, 2001). In the Middle east, the conflict between Palestinians and Israelis have likely contributed to higher than expected fertility levels among the Palestinians (Fargues, 2000). Particularly, in the refugee camps of West Bank and Gaza, political reasons were more important than economic and religious reasons for the increased desire for a large family during the intifada years, 1989-90 (Marwan et al., 2003).

Still others argue that even if some military conflicts are reported to have resulted in short-term fertility changes, most wars are not associated with substantial fertility change. For example, in Lebanon, the civil war and economic crisis had little effect on fertility mainly due to the low fertility levels already reached prior to the civil war (Khlat, et al., 1997). Fertility was the same before and after the 1974-75 famine in Bangladesh (Watkins and Menken, 1985). Similarly, in Rwanda, the most severe crisis of the twentieth century was not found to have any great impact on fertility of that country (Hill, 2004). 
Clearly, the existing literature suggests conflicting expectations. The hypothesis of crisis-led fertility decline remains an empirical question on which there is remarkably little evidence. While extreme conditions involving drought, economic decline, and military conflict have prompted short-term fertility declines, the evidence is not conclusive that such conditions can always lead to fertility decline (Lesthaeghe, 1989; Lindstrom and Berhanu, 1999; Peng, 1987; Watkins and Menken, 1985). Evidence on fertility response to crises has not been demonstrated successfully, particularly for countries in the east African region, including Eritrea. Understanding this relationship is especially critical for countries in this region, which have been affected severely by military conflict and political unrest, and where the transition to lower fertility is at its early stage. Thus, Eritrea becomes an interesting case study for exploring whether the recent border conflict is neutral in effect and the recent fertility decline stems from other factors or not.

\section{Data and method}

The major source of data for this study is the 2002 Eritrea Demographic and Health Survey. This survey covered a nationally representative sample of 9,389 households with 8,754 women of reproductive ages at the time of the survey, of which 6,900 were currently or formerly married. In the trend analysis, data from the 1995 EDHS survey are used in order to measure fertility trend more accurately in the early 1990s. The 1995 survey covered a total of 5,054 women aged 15-49 years, of which about 3,600 were married.

In the trend analysis, annual total fertility and age-and parity-specific fertility rates are estimated and presented for the five years before each survey in order to assess the timing of the fertility change in relation to the onset of the border conflict in 1998-2000. Here, the main issue is that if the recent decline is conflict-led, then fertility change should follow rather than precede the outbreak of the border conflict. By plotting the annual fertility estimates, we can visually examine whether the fertility decline started before or after 1998, which marks the onset of conflict (although its impact may be visible starting in 1999). The purpose of including age-and parity-specific estimates in addition to the summary measure is mainly to explore better the structure of the decline by age and parity.

To ascertain further evidence of the fertility decline and investigate its underlining factors, a multivariate regression analysis is employed. The specific model used is the Cox regression method. This method is preferred because it accurately handles the timing of birth events. The time dimension used in the Cox model analysis differs for first and higher order birth models: in the models for first births, it is time since first 
marriage in models where only data from married women are used (Table 3) and time since women's twelve's birthday in models where data for all women are used (Table 2 ). The rationale for estimating separate first birth models for married women is to explore whether delay in age at marriage has an effect on first birth fertility, as this variable is applicable for married women only. In the models for second and higher order births, the time variable is time since previous birth.

\section{Description of variables}

The dependent variable is whether or not a woman experienced a live birth during the interval that is studied and the timing of that event. The independent variables include calendar period, birth order, age of mother at the birth of the previous child, spacing of births, survival of preceding child, age at first marriage and/or marital status, women's education, region of residence, and childhood rural-urban residence.

In this study, we adopted the simplest way to measure the occurrence of conflict in relation to historical calendar period. This means that we are not able to identify the specific factors responsive for the conflict that may link the border conflict directly or indirectly with fertility (e.g., changes in GNP, living conditions, etc.). The focus is on how fertility changed during the conflict period in comparison to pre-conflict periods. The analysis recognizes 1999 as the starting year of the social and economic effects of the conflict. Calendar period is a time-varying covariate measured by a set of dummy variables.

Previous studies have shown that the likelihood of bearing another child is associated with the length of the preceding birth interval (Nair, 1996; Rodriguez et al., 1984). According to these authors a longer previous birth interval (24 months or more) is associated with a lower probability of a further conception or birth. Data from the EDHS surveys show that the median length of birth interval in 2002 is 2 months longer than that in 1995 (33.4 versus 31.3 months, respectively). This increase in birth interval may be partly attributed to the improvement in child survival in the country. Although there is no general level of child mortality which leads to a fertility decline when it is reached, there is a general consensus that the death of a previous sibling is associated with a shorter than expected birth interval, and similarly with a higher probability of conception or birth (Park et al., 1998; Santow and Bracher, 1984; Lindstrom and Kiros, 2007). In Eritrea, infant mortality declined from 72 to 48 per 1000 live births between 1995 and 2002 (NSEO and ORC Macro Inc., 2003).

Age at first marriage has been recognized as an important determinant of fertility because it marks the beginning of exposure to the risk of childbearing in societies where pre-marital sex is uncommon and where there is little deliberate effort to control 
fertility (Blanc and Rutenberg, 1990; Hinde and Mturi, 2000). However, some studies suggest that the effect of changes in nuptiality on overall fertility is not clear because of substantial fertility among never-married women (Hinde and Mturi 2000; Innocent 2001). In Eritrea, where pre-marital childbearing is uncommon or very low (NSEO and ORC Macro Inc. 1997), delays in marriage can reduce the number of women under risk of childbearing and hence fertility. Thus, in order to check whether delay in age at marriage has a significant effect or not on the recent fertility decline, we have included this variable in the analysis of first births.

The variable region of residence serves as a test criterion for the impact of the border conflict: the assumption is that if the conflict is responsible for initiating the fertility decline, then this decline should be most marked among populations with the more severe experience of conflict. Since two regions, South and Gash Barka, were the hardest hit, one could expect a stronger response in these two regions. Women's education is included to assess if improvement in women's education has an effect on the decline of fertility. Women's education is a significant predictor of fertility in most contexts (Cleland and Wilson, 1987; Martin, 1995; Sathar et al., 1988). Rural-urban residence is included to explore whether there are rural-urban differentials in the recent decline of fertility. It is likely that urban dwellers usually benefit from more and better family planning and health facilities, and better living conditions than rural dwellers. Consequently, urban residence has generally been associated with lower fertility and mortality in most developing countries.

The analysis and interpretation of the association between explanatory variables and fertility is facilitated by estimation of separate models for first and higher order births. This analytical strategy emanates from the fact that some variables have different impacts on fertility at first and higher birth orders. For example, age at first marriage and marital status are more important for first births (onset of reproduction) than for fertility at higher birth orders. Variables like age of woman at birth of previous child, birth order, spacing of previous births, and survival status of the previous sibling are only applicable for higher parities, etc.

\section{Background to Eritrea}

Eritrea lies in the northeastern region of Africa, which also includes Sudan, Djibouti, Ethiopia, Somalia, and Kenya, where fertility is still high - except in Kenya for which fertility decline has been convincingly documented. Eritrea is a small country with a land area of about 125,000 square kilometers and a population size of approximately 3.2 million. Administratively, it is divided into six regions: Southern Red Sea, Anseba, 
Northern Red Sea, Gash Barka, Central and Southern. Three out of every four Eritreans live in rural areas, where people are engaged primarily in subsistence agriculture.

As in other traditional societies, women's worth is measured in terms of their role as mothers and wives, particularly in the rural areas of Eritrea. During the preindependence period, no much effort was made by the Ethiopian regime to change women's subordinate status, which is based on deep-rooted traditional values and beliefs. Women traditionally have suffered socio-cultural and economic discrimination and have had fewer opportunities than men for education, employment, and participation in decision-making activities. In the urban areas, where education, health care and employment outside the home were relatively better, few women with higher education found professional employment: most held low-paying jobs. On the other hand, women who participated in the struggle for independence made a unique contribution, both as fighters and as civilian supporters to challenge and ousting the Ethiopian government. Women were active participants in the social, political, and cultural activities of the communities under the jurisdiction of the Eritrean Peoples Liberation Front, EPLF (now the government of Eritrea). Particularly, women fighters (although a small segment of the population as compared with men) were allowed to participate equally and fully in all sectors of activities performed in the areas administered by the EPLF. Thus, although we do not have any statistical evidence to support our argument, such involvements of women in social, administration and leadership may have facilitated the emergence of new perceptions of their roles and rights that may enable them to make their own decisions. It is also likely that old economic relations, customs, and value systems have been somewhat weakened by the gains in women's status during the struggle and afterwards. But, since women who participated in the struggle were a small segment of the population (the majority, especially in the capital city and other urban areas were under the administration of the Ethiopian government), it is hard to judge their influence on the overall status of women in Eritrea.

Although the intensity of hostilities varied over time, Eritrea suffered through one of the longest and most bitter war for independence in modern Africa (1961-91). After independence, hostilities flared up again with Ethiopia in mid-1998, which continued until 2000. Only between 1992 and mid-1998 has Eritrea lived through a period of relative peace. No official data on the size and distribution of recent and post warrelated population displacement, migration and mortality are available. There is also hardly any available literature on Eritrea's demographic situation in general and fertility in particular until 1995. The only available sources of demographic and reproductive situation are the two EDHS surveys conducted in 1995 and 2002. Although there is no detailed or systematic record on the amount of destruction inflicted by the war for liberation, there is no doubt that it resulted in profound damage to the economy and 
human life. In general, prolonged war and military tensions with Ethiopia in combination with cycles of drought and lingering poverty made life very tough in Eritrea prior to independence.

The attainment of Eritrea's independence in mid-1991 fostered high expectations that it would create new opportunity for socio-economic development. As anticipated, progress was made between 1992 and mid-1998. Some available reports show that Eritrea's GDP grew at an average rate of 7\% per annum between 1992 and 1997 (UN, 2002). Total government expenditure grew by $79 \%$ during this period. There were major investments in extending health care and education services. As a result, immunization coverage was expanded and polio was close to being eliminated and infant and child mortality rates declined sharply (NSEO and ORC Macro, 2003). The primary school gross enrolment ratio increased from 36\% in 1992 to 52\% in 1997 (Ministry of Education, 2002). Primary analysis from the two EDHS surveys also shows that the proportion of women in the reproductive ages with primary or higher education has increased from about 34\% in 1995 to $50 \%$ in 2002.

Unfortunately, Eritrea's initial promising socio-economic growth was disrupted by the unexpected border conflict with Ethiopia that started in May 1998 and resulted in a war that continued until 2000. This conflict has reversed much of the progress that Eritrea made during 1992-1997. The war has not only caused loss of human life, displacement of nearly one-third of the total population (about one million people), but has also reversed much of the progress in socio-economic trends made during the postindependence - pre-conflict period (UN, 2002). For instance, the growth of GDP declined from about $7 \%$ annually during $1992-1997$ to $4 \%$ in $1998,1 \%$ in 1999 , and a negative growth of $8 \%$ in 2000; inflation rose from an average of 6\% during 1994-1997 to $27 \%$ in 2000; and the fiscal deficit increased from 6\% of GDP in 1997 to $48 \%$ of GDP in 2000 (UN, 2002). Prices of food and other commodities rose rapidly starting in late 1998 and continued to rise in subsequent years.

The border conflict also resulted in the military mobilization of all Eritreans, but mostly of males aged 18-40 years. It is certain that such mobilization has decreased the proportion of married couples living together. A comparison of the proportions of married women residing with their husbands at the time of the 1995 and 2002 EDHS surveys shows a significant decline in all age groups (see Table 1) and particularly at younger ages. For example, only three in ten married women aged 15-19 were living with their husband in 2002, while the corresponding figure was six in ten in 1995. One would expect that separation of couples have reduced married women's exposure to the risk of pregnancy. A review of evidence on the fertility response to war and population displacement of women in Sarajevo before and during the Bosnian war in 1992-94 showed that in the short-term fertility fell mainly as a result of temporary separation (Hill, 2004). 
Table 1: $\quad$ Percent ever married and percent of married women residing with husband, by age

\begin{tabular}{lllll}
\hline Current & \multicolumn{2}{l}{ Ever married } & & \multicolumn{2}{l}{ Residing with husbands } \\
\cline { 2 - 5 } Age & 1995 & 2002 & 1995 & 2002 \\
\hline $15-19$ & 37.6 & 31.0 & 60.4 & 30.5 \\
$20-24$ & 78.1 & 72.7 & 74.4 & 42.1 \\
$25-29$ & 92.1 & 88.5 & 79.1 & 48.9 \\
$30-34$ & 95.8 & 95.4 & 84.0 & 60.6 \\
$35-39$ & 98.2 & 97.8 & 88.4 & 72.4 \\
$40-44$ & 97.3 & 99.0 & 89.0 & 78.9 \\
$45-49$ & 98.1 & 99.2 & 90.6 & 88.0 \\
Total & 80.0 & 76.7 & 80.9 & 58.5 \\
\hline
\end{tabular}

The figures are calculated from the 1995 and 2002 EDHS data files

\section{Fertility development}

\subsection{Timing of the fertility decline: Trend analysis for 1990-2001}

Using the event-history data from the 1995 and 2002 EDHS surveys, we begin our investigation of trends in fertility in Eritrea by estimating annual total fertility rates (TFR), and age- and parity-specific fertility rates (ASFR and PSFR). These are plotted in Figures 1, 2 and 3, respectively, by single calendar year for five years prior to the 1995 survey and seven years before the 2002 survey. In later sections, further analysis is made using multivariate regression techniques to explore the nature of the trend and its possible underlying factors.

It is clear from Figure 1 that fertility was relatively high (between 7.0 and 6.0) with some fluctuations before 1998, and subsequently declined to a level of 4.5 in 1999-2000 with a slight increase in 2001. From this trend, the decline is more noticeable after 1998 and based on data from both surveys there is no clear indication that a consistent decline started before 1998. This is consistent with Blanc's (2004) findings. Although there is no logical reason that can explain the sudden fertility increase in 1998, the clear and rapid decline in fertility during the period 1999-2001 is likely to be due to the interference of the border conflict. The slight increase in fertility in the year just prior to the 2002 survey may be genuine due to the relative peace after 2000 or due to more accurate reporting of births during the year immediately preceding the survey (Institute for Resource Development, 1990). 
In addition to the TFRs, age-and parity-specific fertility rates (ASFRS and PSFRS) are calculated and plotted by calendar year in order to find out whether the change in fertility is particularly pronounced at younger or older ages of women and at lower or higher order births. These are summarized in Figures 2 and 3, respectively. The ASFRS and PSFRS in Figures 2 and 3 support the above observation that fertility was high in the early and mid-1990s, followed by a downward trend after 1998, and the decline seems to have occurred at all reproductive ages and birth orders. It is worth noting here that the irregularities (peaks and troughs) shown at certain calendar years and at certain ages or parities can be either due to genuine fluctuations in fertility because of the changing circumstances in Eritrea from year to year, or these fluctuations can be due to misreporting errors such as shifting of births or ages of women. It should also be remembered that the figures are for single calendar years and are thus affected by random fluctuations.

Figure 1: Estimates of total fertility rate for single calendar years prior to the 1995 and 2002 EDHS

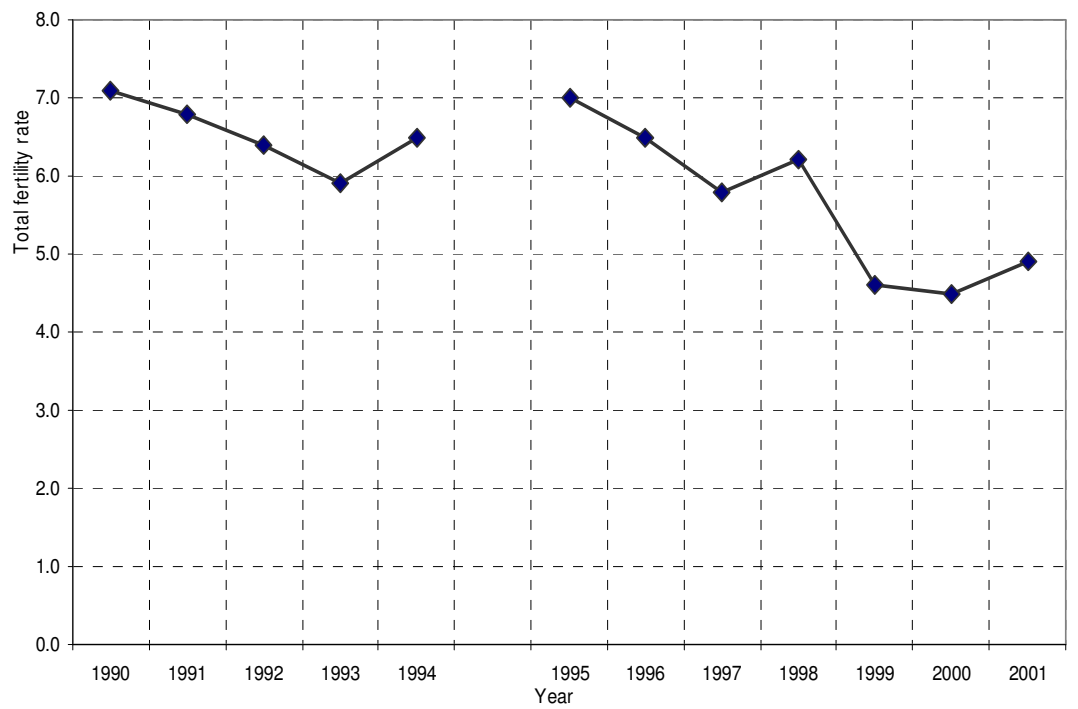


Figure 2: Estimates of age-specific fertility rates for single calendar years prior to the 1995 and 2002 EDHS

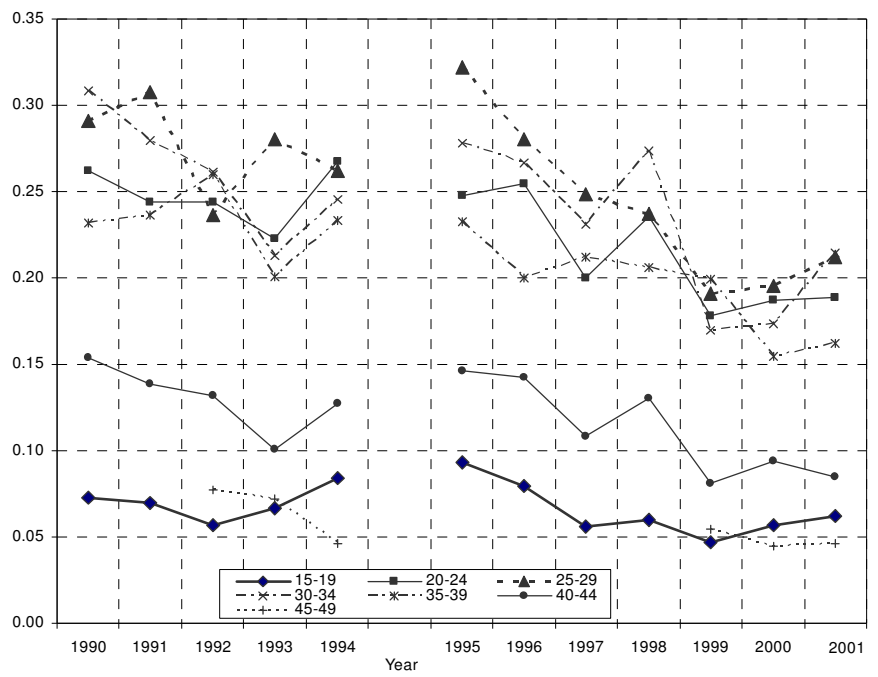

Figure 3: Estimates of parity-specific fertility rates for single calendar years prior to the 1995 and 2002 EDHS

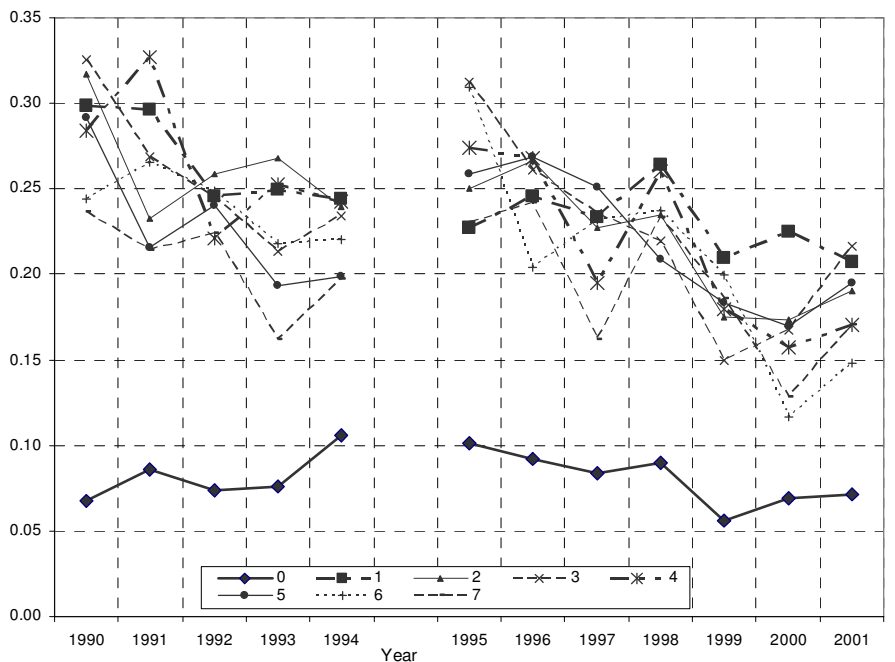




\subsection{Multivariate analysis}

The above trend analyses of aggregate fertility measures indicate that the decline in fertility is certainly noticeable after 1998 and that it occurred at all ages and birth orders. But, such aggregate measures may not be robust enough to discern the underlying trend of the decline and do not capture the impact of compositional changes among women and of change in reproductive behavioral factors related to family size limitation, including changes in birth spacing, parity, child survival status, marital status, and other socio-demographic factors. In order to further investigate in-depth whether a clear change in fertility is visible before or after 1998, multivariate regression methods are used to estimate separate models for first and higher order births.

The results of the multivariate analyses are given as relative risks of giving birth to a (another) child, where the risk of giving birth is expressed relative to a reference (or baseline) category of each covariate. A relative risk of 1 indicates that the estimated risk is equal to that of the reference category; a relative risk greater than 1 indicates that fertility is higher than that of the reference category and a relative risk less than 1 indicates lower fertility than for the reference category.

Tables 2 and 3 present the results from the multivariate analyses of first births of all women and of married women, respectively. Relative risks associated with calendar years indicate how much fertility has changed relative to the reference level, 1996-98. It is evident from these tables that there has been a gradual increase in first birth fertility until 1996-98, and a subsequent decline after this period. This clearly suggests that first birth fertility increased during the post-independence period when Eritrea enjoyed peace and economic improvements during 1992-98 and started to decline after 1998 during the border conflict. The later development may be due to the impact of mobilization of young married Eritreans to the military service during the border conflict. The effect of calendar period remains largely consistent and statistically significant even with the addition of marital status and other variables to the model.

Rural-urban differentials indicate that first birth fertility is lower in urban than in rural areas (Model 1, Table 2). Fertility is considerably higher among ever-married than among never-married women. Adding marital status in the model reversed the ruralurban differential in first birth fertility. This suggests that rural-urban differential in first birth fertility is not due to rural-urban residence per se, but to differences in marital status between rural and urban areas with many rural women getting married at younger ages which do not give birth immediately after marriage, probably because they are either physiologically immature or are still staying with their parents, which is often the case in rural Eritrea. Model 3 of Table 2 shows no significant difference in first birth fertility among the different regions, except for the South region where the risk of having a first birth is higher than in the other regions. This region is one of the two regions where the population is most affected by the border conflict. In order to assess 
fertility differentials by region of residence, an interaction model between calendar period and region was run (not presented here). But, no important regional differences in fertility trends in first births were found.

Table 2: $\quad$ Relative risks of first birth associated with selected variables

\begin{tabular}{|c|c|c|c|}
\hline Variables & Model 1 & Model 2 & Model 3 \\
\hline \multicolumn{4}{|l|}{ Period $^{t}$} \\
\hline$<1990$ & $0.71^{* * *}$ & $0.63^{* * *}$ & $0.61^{* * *}$ \\
\hline $1990-92$ & $0.82^{* * *}$ & $0.79^{* * *}$ & $0.80^{\star * *}$ \\
\hline 1993-95 & $0.93^{*}$ & $0.88^{\star * *}$ & $0.80^{* * *}$ \\
\hline $1996-98$ & 1 & 1 & 1 \\
\hline $1999-01$ & $0.72^{* * *}$ & $0.75^{* * *}$ & $0.76^{\star * *}$ \\
\hline \multicolumn{4}{|c|}{ Childhood residence } \\
\hline Rural & 1 & 1 & 1 \\
\hline Urban & $0.62^{* * *}$ & $1.14^{\star \star \star}$ & $1.13^{\star * \star}$ \\
\hline \multicolumn{4}{|l|}{ Marital status ${ }^{t}$} \\
\hline Ever-married & - & 1 & 1 \\
\hline Never married & - & $0.05^{\star \star \star}$ & $0.05^{\star \star \star}$ \\
\hline \multicolumn{4}{|l|}{ Region } \\
\hline Southern Red Sea & - & - & 1 \\
\hline Central & - & - & $1.09^{*}$ \\
\hline Northern Red Sea & - & - & 0.95 \\
\hline Anseba & - & - & 1.04 \\
\hline Gash Barka & - & - & 0.95 \\
\hline South & - & - & $1.17^{* * *}$ \\
\hline \multicolumn{2}{|c|}{ Change in degrees of freedom $(\Delta \mathrm{df})$} & 1 & 5 \\
\hline \multicolumn{2}{|c|}{ Change in model statistic ( $\Delta \chi^{2}$ statistic) } & 7144.80 & 265.13 \\
\hline
\end{tabular}

${ }^{*}$ Factor level significant at $<10 \%$

** significant at $<5 \%$

***significant at $<1 \%$

${ }^{\mathrm{t}}$ Time varying covariates

Table 3 considers only married women. The data from Table 3 suggest the same fertility trend by period as in Table 2 . In addition, first birth fertility is higher among women who married at older ages than those married at young ages. Evidently, those who marry late give their first birth very fast after marriage while those who marry very early delay their first birth. In Eritrea, where most marriages start very early (particularly in rural areas), women often stay at their parents' home for several years after getting married. This is likely to prolong the interval between marriage and first birth and hence reduce first birth fertility. Our finding is consistent with results from a 
study in rural Anhui, China (Yang, 1990) who found women who married at an older age had a higher fertility rate for the first five years of marriage, while younger married women had a lower initial fertility rate. A higher level of woman's education is believed to be associated with lower level of fertility (e.g., UN, 1987; Freedman et al., 1988). The negative effect of education on fertility may work through several mechanisms (Knodel and Pitaktepsombati, 1973; Martin and Juarez, 1995): first, education may raise age at marriage by postponing marriage in order to complete higher education, second, education can lead to enhancement of women's ability to make reproductive choices, such as greater use of contraception and postponement of childbearing, and to achieve desired low family size. However, unlike in other countries, neither higher education of women nor higher age at first marriage led to lower first birth fertility in Eritrea. This may suggest that educated women marry at higher ages (NSEO and ORC Macro Inc., 2003) and once they are married, they rapidly enter into motherhood.

Table 4 displays the results from the multivariate analyses of second and higher order births. Unlike with first birth fertility, this table shows that all relative risks before the reference period are significantly above unity, and the decline has started sometime between 1996 and 1998, that is, before the conflict. This may suggest that women started to postpone or limit childbearing after they reach the desired number of children. Like with first births, the addition of other variables makes no significant difference on the period-fertility relationship. The results show that fertility is lower among women older than 35 years, but otherwise not much affected by age. The pattern by birth order also shows that, net of all the socio-demographic influences (Models 4 and 5), fertility is lower at the very high birth orders, but mostly not very strongly affected by birth order. The effects of rural-urban childhood residence and education of women is in the expected direction and statistically significant, where fertility is lower among women with some education and who lived in urban areas during childhood.

The effect of previous birth interval is clear and significant, where longer birth intervals are associated with lower fertility. The death of a previous child also increases the probability of having the next birth. The risk of conception is about $30 \%$ higher if the previous sibling has died than if it is alive, thus confirming the common finding that death of a previous child is correlated with the next conception (Lindstrom and Kiros, 2007). There is no systematic differential in fertility by region, although fertility is relatively lower in three regions, Central, Northern Red Sea, and Gash Barka. 
Table 3: Relative risks of first birth of married women associated with selected variables

\begin{tabular}{|c|c|c|c|c|}
\hline Variable & Model 1 & Model 2 & Model 3 & Model 4 \\
\hline \multicolumn{5}{|l|}{ Period $^{t}$} \\
\hline$<1990$ & $0.57^{\star \star *}$ & $0.61^{* * *}$ & $0.62^{* * *}$ & $0.62^{* * *}$ \\
\hline $1990-92$ & $0.75^{\star \star *}$ & $0.77^{\star * *}$ & $0.78^{* * *}$ & $0.78^{* * *}$ \\
\hline 1993-95 & $0.85^{* * *}$ & $0.86^{\star * *}$ & $0.87^{\star \star *}$ & $0.87^{\star * *}$ \\
\hline $1996-98$ & 1 & 1 & 1 & 1 \\
\hline $1999-01$ & $0.77^{\star * *}$ & $0.75^{\star \star *}$ & $0.75^{\star \star \star}$ & $0.75^{\star \star *}$ \\
\hline \multicolumn{5}{|l|}{ Childhood residence } \\
\hline Rural & 1 & 1 & 1 & 1 \\
\hline Urban & $1.25^{\star * *}$ & $1.18^{\star * *}$ & 1.08 & 1.09 \\
\hline \multicolumn{5}{|l|}{ Age at $1^{\text {st }}$ marriage } \\
\hline$<16$ & - & 1 & 1 & 1 \\
\hline $16-19$ & - & $1.39^{\star * *}$ & $1.38^{\star \star *}$ & $1.38^{\star * *}$ \\
\hline $20+$ & - & $1.58^{* * *}$ & $1.58^{\star * *}$ & $1.58^{* * *}$ \\
\hline \multicolumn{5}{|l|}{ Education of mother } \\
\hline No education & - & - & 1 & 1 \\
\hline Primary & - & - & $1.16^{\star \star \star}$ & $1.14^{\star * *}$ \\
\hline \multicolumn{5}{|l|}{ Region } \\
\hline Southern Red Sea & - & - & - & 1 \\
\hline Central & - & - & - & 1.00 \\
\hline Northern Red Sea & - & - & - & 1.01 \\
\hline Anseba & - & - & - & 1.07 \\
\hline Gash Barka & - & - & - & 0.93 \\
\hline South & - & - & - & 1.06 \\
\hline \multicolumn{2}{|c|}{ Change in degrees of freedom $(\Delta \mathrm{df})$} & 2 & 2 & 5 \\
\hline \multicolumn{2}{|c|}{ Change in model statistic ( $\Delta \chi^{2}$ statistic) } & 187.10 & 20.56 & 11.95 \\
\hline
\end{tabular}

${ }^{\star}$ Factor level significant at $<10 \%$

*** significant at $<1 \%$

${ }^{\mathrm{t}}$ Time varying covariate 
Woldemicael: Recent fertility decline in Eritrea

Table 4: $\quad$ Relative risks of higher order births associated with selected socio-demographic variables

\begin{tabular}{|c|c|c|c|c|c|}
\hline Variable & Model 1 & Model 2 & Model 3 & Model 4 & Model 5 \\
\hline \multicolumn{6}{|l|}{ Period $^{t}$} \\
\hline$<1990$ & $1.09^{* \star *}$ & $1.08^{* * *}$ & $1.06^{\star \star}$ & 1.03 & 1.03 \\
\hline $1990-92$ & $1.25^{\star * *}$ & $1.24^{* * *}$ & $1.22^{* * *}$ & $1.19^{* * *}$ & $1.19^{* \star *}$ \\
\hline 1993-95 & $1.26^{* * *}$ & $1.26^{* * *}$ & $1.25^{\star *}$ & $1.23^{* * *}$ & $1.23^{* *}$ \\
\hline 1996-98 & 1 & 1 & 1 & 1 & 1 \\
\hline $1999-01$ & $0.75^{\star \star \star}$ & $0.75^{\star \star \star}$ & $0.76^{\star \star \star}$ & $0.77^{\star \star \star}$ & $0.77^{\star \star \star}$ \\
\hline \multicolumn{6}{|c|}{ Age of mother at previous birth } \\
\hline$<20$ & 1 & 1 & 1 & 1 & 1 \\
\hline $20-24$ & $1.05^{* *}$ & $1.05^{\star}$ & $1.05^{\star *}$ & $1.10^{* * *}$ & $1.10^{* \star *}$ \\
\hline $25-29$ & 1.04 & $1.04^{*}$ & $1.04^{*}$ & $1.14^{\star \star *}$ & $1.13^{* \star *}$ \\
\hline $30-34$ & $0.96^{\star *}$ & 0.96 & 0.96 & $1.09^{* * *}$ & $1.08^{* *}$ \\
\hline $35-39$ & $0.78^{* * *}$ & $0.78^{* * *}$ & $0.77^{\star \star *}$ & $0.91^{* *}$ & $0.90^{* *}$ \\
\hline $40-49$ & $0.55^{\star \star \star}$ & $0.55^{\star * *}$ & $0.54^{\star * *}$ & $0.65^{\star * \star}$ & $0.64^{\star * *}$ \\
\hline \multicolumn{6}{|l|}{ Birth order } \\
\hline $2-3$ & 1 & 1 & 1 & 1 & 1 \\
\hline $4-5$ & 1.01 & 1.00 & 0.99 & $0.94^{* * *}$ & $0.94^{\star *}$ \\
\hline $6-7$ & 1.00 & 0.98 & 0.96 & $0.88^{* * *}$ & $0.88^{* * *}$ \\
\hline $8+$ & $0.88^{\star \star *}$ & $0.87^{* * *}$ & $0.84^{* * *}$ & $0.76^{\star * \star}$ & $0.77^{\star * \star}$ \\
\hline \multicolumn{6}{|l|}{ Childhood residence } \\
\hline Rural & - & 1 & 1 & 1 & 1 \\
\hline Urban & - & $0.78^{* * *}$ & $0.92^{* * *}$ & $0.92^{\star * *}$ & $0.92^{\star \star *}$ \\
\hline \multicolumn{6}{|l|}{ Education of mother } \\
\hline No education & - & - & 1 & 1 & 1 \\
\hline Primary & - & - & $0.85^{\star \star *}$ & $0.85^{\star \star *}$ & $0.85^{\star \star \star}$ \\
\hline Secondary or higher & - & - & $0.66^{\star * \star}$ & $0.65^{\star \star \star}$ & $0.66^{\star \star \star}$ \\
\hline \multicolumn{6}{|c|}{ Previous birth interval $^{\$}$} \\
\hline$<18$ & - & - & - & 1 & 1 \\
\hline $18-23$ & - & - & - & $0.94^{\star \star \star}$ & $0.94^{\star \star \star}$ \\
\hline $24-35$ & - & - & - & $0.90^{\star * *}$ & $0.90^{\star * *}$ \\
\hline $36-47$ & - & - & - & $0.79^{\star \star \star}$ & $0.79^{\star \star \star}$ \\
\hline $48+$ & - & - & - & $0.72^{\star \star \star}$ & $0.72^{\star \star \star}$ \\
\hline \multicolumn{6}{|c|}{ Survival of preceding birth ${ }^{t}$} \\
\hline Living & & & & 1 & 1 \\
\hline Dead & & & & $1.32^{\star \star *}$ & $1.33^{\star \star \star}$ \\
\hline
\end{tabular}


Table 4: (continued)

\begin{tabular}{llllll}
\hline Variable & Model 1 & Model 2 & Model 3 & Model 4 & Model 5 \\
\hline Region & - & - & - & - & 1 \\
Southern Red Sea & - & - & - & - & $0.93^{* *}$ \\
Central & - & - & - & - & $0.94^{* *}$ \\
Northern Red Sea & - & - & - & - & 1.02 \\
Anseba & - & - & - & - & $0.94^{* *}$ \\
Gash Barka & - & - & - & - & 0.99 \\
South & 1 & 2 & 5 & 5 \\
\hline Change in degrees of freedom $(\Delta$ df) & 96.12 & 131.58 & 214.85 & 21.41 \\
Change in model statistic $\left(\Delta \chi^{2}\right.$ statistic) & & & & \\
\hline & & & & \\
${ }^{*}$ Factor level significant at $<10 \%$ \\
${ }^{* *}$ significant at $<5 \%$ \\
${ }^{* * *}$ significant at $<1 \%$ \\
Time varying covariate \\
${ }^{\$}$ For second births the interval is from first marriage to first birth
\end{tabular}

Overall, it is evident from the multivariate models that fertility in Eritrea has declined in recent years and the onset of the decline seems to vary by birth order. While it is clear from Tables 2 and 3 that the decline in first birth fertility occurred after 1998, for second and higher order births, the decline did not follow 1998. It rather started prior to 1998 , well before the conflict.

In the final model of Table 4, all possible interactions were also explored, and interactions of calendar period with birth order, age of mother at the birth of the previous child, and with region were found to be significant. Summaries of these interactions are presented in Tables 5, 6, and 7, respectively. Interactions that are not statistically significant are not shown. For instance, we run interactions of period with education and rural-urban residence to assess if the later factors have interacting effects on fertility in addition to their independent effects, but found no such effects. In our presentation of interaction results (Tables 5, 6, and 7), we have recalculated the relative risks of each combination of calendar period and the other variable of interest so that the risks for each category of birth order, age at previous birth, and region are given relative to that of 1996-98. This provides a more lucid overview of the period developments over the factors we consider.

The results in Tables 5, 6 and 7 indicate a consistent and significant lower fertility after 1995 for all birth orders, age groups, and regions, although the fertility response is strongest during the most recent period (1999-01). The fertility decline is relatively stronger among higher order births (4 or higher) and older women (35 or older). Although one may expect that the two regions, South and Gash Barka, which were 
relatively more affected in terms of population displacement, direct fighting, etc during the border conflict to have experienced lower fertility, no differential fertility response is observed in these regions. However, it is to be noted that region of residence is a potentially very problematic variable, since it is measured only at the time of the interview. The absence of information on migration histories during a period of much forced migration and displacement makes results of this variable to appear very tentative.

Table 5: Interaction effect of calendar period and birth order on fertility of $2^{\text {nd }}$ and higher births: risks for period before $1996 \& 1999-01$ relative to the period 1996-98

\begin{tabular}{lllll}
\hline Birth order & & & & \\
& & & & \\
\hline Period & $2-3$ & $4-5$ & $6-7$ & $8+$ \\
\hline Before 1996 & 1.14 & 1.17 & 1.10 & 1.13 \\
$1996-98$ & 1 & 1 & 1 & 1 \\
$1999-01$ & 0.83 & 0.75 & 0.70 & 0.75 \\
\hline $\begin{array}{l}\text { Change in degrees of freedom }(\Delta \text { df) } \\
\begin{array}{l}\text { Change in model statistic }\left(\Delta \chi^{2} \text { statistic }\right) \\
\text { p }=0.000\end{array}\end{array}$ & $\begin{array}{l}14.50 \\
\end{array}$
\end{tabular}

Table 6: Interaction effect of calendar period and age of mother on fertility of $2^{\text {nd }}$ and higher births: risks for the periods before $1996 \&$ 1999-01 relative to the period 1996-98

\begin{tabular}{|c|c|c|c|c|c|c|}
\hline \multicolumn{7}{|c|}{ Age of mother at birth of previous child } \\
\hline Period & $\leq 19$ & $20-24$ & $25-29$ & $30-34$ & $35-39$ & $40-49$ \\
\hline Before 1996 & 1.17 & 1.12 & 1.09 & 1.16 & 1.31 & 1.80 \\
\hline $1996-98$ & 1 & 1 & 1 & 1 & 1 & 1 \\
\hline $1999-01$ & 0.92 & 0.78 & 0.72 & 0.78 & 0.69 & 0.59 \\
\hline \multicolumn{3}{|c|}{ Change in degrees of freedom $(\Delta \mathrm{df})$} & 10 & & & \\
\hline \multicolumn{3}{|c|}{$\begin{array}{l}\text { Change in model statistic ( } \Delta \chi^{2} \text { statistic) } \\
p=0.000\end{array}$} & 45.17 & & & \\
\hline
\end{tabular}


Table 7: Interaction effects of calendar period and region on fertility of $2^{\text {nd }}$ and higher births: risks for period 1999-2002 relative to those of period before 1999

\begin{tabular}{|c|c|c|c|c|c|c|}
\hline \multicolumn{7}{|l|}{ Region } \\
\hline Period & $\begin{array}{l}\text { Southern } \\
\text { Red Sea }\end{array}$ & Central & $\begin{array}{l}\text { Northern } \\
\text { Red Sea }\end{array}$ & Anseba & $\begin{array}{l}\text { Gash } \\
\text { Barka }\end{array}$ & South \\
\hline Before & 1.14 & 1.20 & 1.28 & 1.16 & 1.16 & 1.99 \\
\hline \multicolumn{7}{|l|}{1996} \\
\hline \multicolumn{7}{|l|}{$1996-98$} \\
\hline 1999-01 & 0.66 & 0.78 & 0.89 & 0.80 & 0.77 & 0.72 \\
\hline Change i & grees of fre & $(\Delta d f)$ & 10 & & & \\
\hline $\begin{array}{l}\text { Change i } \\
p=0.000\end{array}$ & del statistic & statistic) & 33.43 & & & \\
\hline
\end{tabular}

Note: In the interactions calendar period is collapsed into three categories

\section{Discussion and conclusion}

In this study, an attempt was made to examine the recent fertility decline in Eritrea, a setting that experienced a violent conflict and economic crisis in recent years. The purpose was to improve our understanding of the timing of the fertility decline and the underlying factors that contributed to it. It argues that looking solely at the changes in TFR is not adequate to give a clear picture and understanding of the nature and causes of the decline. This may lead to inappropriate policy options by failing to take into account the relative importance of the different factors that affect fertility.

The findings from our trend analysis of TFR and age-and parity-specific fertility show that the magnitude and trend of the fertility decline is fairly consistent with those reported by Blanc (2004). Our multivariate analysis revealed a different pattern of fertility decline for first and higher order births. For first births, the decline is only noticeable after 1998 (the onset of the conflict), while for higher order births the decline started well before 1998. Thus, Blanc's generalization that the border war of 1998 to 2000 was the driving force behind the onset of the decline cannot be entirely confirmed from our study for the following reasons: First, the fact that the fertility decline of higher order births started before the conflict rather supports our argument that part of the decline may be due to a more long-term fertility transition than a short-term development initiated by the conflict. This does not rule out the effects of the conflict in 
initiating the first birth fertility decline. Second, our results from the interactions of calendar period with age of mother and with birth order clearly showed that although the decline occurs at all ages and at all birth orders, it is relatively stronger among older mothers (35 years or older) and higher order parities (4 or more). Such a pattern may suggest that many couples have purposely delayed or stopped childbearing after they achieved the desired number of children. This part of the fertility decline is likely to be a more long-term development. Third, if the conflict had been the sole factor responsible for the decline, a stronger decline could have been observed in the two regions which were most severely affected by the fighting. But, we did not find any significant regional differences in fertility trends; rather the decline occurred in all regions. Fourth, improvements in education and child survival and increased urbanization, which all pre-dated the conflict are likely to have had some impacts on fertility aspirations and consequently in the decline of fertility, although the mechanisms through which these factors have affected fertility are not clear from our study. Overall, the evidence of this study is that the decline in marital fertility is the main contributor to the overall fertility decline although a delay in age at first marriage and an increase in the proportion of never married women have played some role in the decline of births too. Part of the decline thus, appears to indicate the onset of a longterm fertility transition, which is likely to be related to improvements in access to healthcare services, education, and increased urbanization which pre-dated the conflict. We are careful to point out that we do not find strong direct support for the role of socio-demographic factors in the fertility decline that we observe. This may partly be due to the cross-sectional character of much of our data, where we cannot keep proper track of changes over time in the composition of women over educational and employment histories, rural-urban residence, and other factors of importance.

However, although we cannot say that the recent decline of fertility in Eritrea is the outcome of the border conflict only, this does not mean that the conflict is neutral in effect. Particularly, the decline of first birth fertility after 1998 might indicate such a war effect. In addition, the border war may have accelerated the ongoing decline of higher order births. Conditions of warfare and the atmosphere of uncertainty they generate may discourage couples from having children or at least make them postpone the next birth, even in the absence of an enduring preference for longer birth intervals or smaller family (Agadjania and Ndola, 2002). The war can affect fertility through changes in proximate determinants such as increased incidence and duration of marital separation (see Table 1) and lower frequency of intercourse, which both are outcomes of the military mobilization. Although the direct effects of these factors cannot be assessed in this study, it is likely that they can have short-term effects on fertility (Agadjania and Ndola, 2002). Thus, it is reasonable to suggest that the fertility decline 
reflects a long-term fertility transition which is further fuelled by a temporary impact of the border conflict and the economic crisis associated with it.

The findings of this study have methodological and theoretical implications. Methodologically, they highlight the importance of examining all parities and ages in a dynamic setup to the extent that data of that kind are available. Studies which do not explicitly focus on first and higher order births, on younger and older ages of women and survival status of preceding child and/or birth spacing are likely to miss important parts of the fertility dynamics and behaviours. Our findings have also implications for theories about fertility change in times of crises in that military conflict may affect certain social groups in the population and cause a short-term decline. The fact that the fertility response to the conflict seems to be important among first births implies that not all groups of the population may be uniformly affected by war crisis or exhibit the same fertility response. The results also imply that war crisis may fuel an ongoing decline, with an assumed subsequent recovery in peace time (Palloni et al., 1996). Note that the data used in this study do not allow any conclusion about the duration of the war-induced decline. These findings support the results from recent studies on fertility during crisis periods in Ethiopia (Lindstrom and Berhanu, 1999), Angola (Agadjania and Ndola, 2002), and Rwanda (Hill, 2004) which are also inconclusive in terms of consistent and sustainable changes in fertility.

Although our study has addressed several important aspects of the recent changes in fertility in Eritrea and its underlying factors, there are still questions which we could not address. The effects of some important factors could not be explored because of either lack of information or deficiency in the data that were collected. The most important ones are the lack of time-varying information on socio-economic indicators, data on spousal separation, and indicators of women's autonomy or status. For example, data limitation prevented us from evaluating further the impact of socio-economic status on fertility: this holds both for individual-level data and macro data on economic developments in different areas of Eritrea. Changes in such socio-economic indicators may affect fertility differently in different time periods. In addition, increase in spousal separation is likely to be one of the potential factors that contributed to the recent change in fertility. Lindstrom and Berhanu (1999) found that spousal separation was one of the mechanisms by which the civil war affected fertility during the short-term in Ethiopia. In the present study, since information on the exact timing of spousal separation is not available for our analyses, we are unable to consider this variable in our dynamic analyses. Improvement in women's status is also suggested to be an important indicator of women's ability to control their fertility (Hindin, 2000; Mason, 1993). It is argued that the lag in fertility decline and contraceptive use in developing countries, particularly in Africa is often attributed to gender inequality and patriarchy which encourages high fertility through the separate roles it assigns to men and women 
(Balk, 1994; Caldwell and Caldwell, 1985; Morgan and Niraula, 1995). However, the amount of patriarchal control over women varies from place to place, could change over time and could be influenced by several other factors. In Eritrea, for instance, women fighters during the struggle for independence were active participants in the social, political and leadership of the liberation front. Such improvements in women's participation might have affected the roles of women in Eritrea. It is likely that women have enjoyed some level of autonomy which avails them the opportunity to take independent decisions on certain issues of reproduction and fertility, but due to lack of timely information on the amount of progress gained in women's individual autonomy we could not assess its effect on fertility.

Finally, given the present political and economic situation of the country, it seems difficult to predict the future course of fertility in Eritrea. However, on the basis of our findings of an emerging pattern of fertility limitation that was initiated before the outbreak of conflict it seems reasonable to assume that fertility in Eritrea will continue to decline gradually in the long-term perspective. The magnitude and nature of that decline is likely to depend on the socio-economic development and the political stability of the country. If the border conflict, which is still unresolved, continues or fighting resumes fertility may continue to be more depressed than what it otherwise would have been. This would be due to continued spousal separation and other fertility inhibiting influences of the conflict. Such an impact may or may not be followed by a temporary recovery of fertility by means of a short-term peace-time fertility boom. Our main prediction is nevertheless that the long-term development in Eritrea is set towards a reduced fertility.

\section{Acknowledgements}

The data used are from the EDHS surveys collected by the National Statistics and Evaluation Office (NSEO) of Eritrea in collaboration with MACRO ORC Inc in 1995 and 2002. I am grateful to these offices for providing me the data. The study was made partly at the Max Planck Institute for Demographic Research, Rostock, Germany and partly at the Stockholm University Demography Unit, Sweden. I would like to express my gratitude to the support of Professor Jan M. Hoem at the Max Planck Institute, Professor Elizabeth Thomson at Stockholm University and the Swedish Council for Working Life and Social Research (FAS). I would also like to thank Gunnar Andersson for helpful advice during the analyses and for valuable comments on the various drafts of this paper, and Dr Andres Vikat who was helpful in providing advice for the trend analysis. I am also grateful to the anonymous reviewers of Demographic Research for their helpful comments and suggestions. 


\section{References}

Abbasi-Shavazi, M.J. (2001) "Recent changes and the future of fertility in Iran." http://www.un.org/esa/population/publications/completingfertility/2RevisedAB BAS1paper.pdf

Agadjanian, V. and Ndola P. (2002) "War, peace, and fertility in Angola." Demography, 39(2): 215-231.

Andersson, G. (1999a). Trends in Childbearing and Nuptiality in Sweden: A Period Analysis. Doctoral Dissertation, Stockholm University Demography Unit.

Andersson, G. (1999b). "Childbearing trends in Sweden, 1961-1997." European Journal of Population, 15: 1-24.

Avogo, W. and Agadjanian, V. (2007). Reproduction in crisis: war, migration and fertility in Angola. A paper presented at the Population Association of America 2007 Annual Meeting Program. March 29-31, 2007, New York.

Balk, D. (1994) "Individual and community aspects of women's status and fertility in rural Bangladesh.” Population Studies, 48(1): 21-45.

Basu, A. M. and Amin, S. (2000). "Conditioning factors for fertility decline in Bengal: History, language identity and openness to innovations." Population and Development Review, 26(4): 761-794

Blanc, A. K. 2004. "The role of conflict in the rapid fertility decline in Eritrea and prospects for the future." Studies in Family Planning, 35(4): 236-245.

Blanc, A.K. and Rutenberg, N. (1990). Assessment of the qualitative of data at first sex, age at first marriage and age at first birth. Demographic and Health Surveys. In Assessment of DHS-I Data Quality. Institute for Resource Development. DHS Methodological Reports, no. 1. Columbia, Maryland.

Bongaarts, J. and Potter, R.G. (1983). Fertility, Biology and Behavior: An Analysis of the Proximate Determinants. Academic Press. New York and London

Bongaarts, J. (1978). "A Framework for analyzing the proximate determinants of fertility." Population and Development Review, 4(1): 105-132.

Bongaarts, J., Frank, O., and Lesthaeghe, R. (1984). "The proximate determinants of fertility in sub-Saharan Africa." Population and Development Review, 10(3): 511-537. 
Boserup, E. (1985). "Economic and Demographic Interrelationships in sub-Sahara Africa." Population and Development Review, 11(3): 383-397.

Bulatao, R. and Casterline, J. (eds.) (2001). Global Fertility Transition, Vol 27. Pp. 116. Population Council, New York.

Busza, J. and Lush, L. (1999). "Planning reproductive health in conflict: a conceptual framework." Social Science and Medicine, 49(2): 155-171.

Caldwell, J.C. and Caldwell, P. (1985) "The cultural forces tending to sustain high fertility in tropical Africa," Washington DC: World Bank, Population, Health and Nutrition Department, PNH Technical Note, 66pp.

CEPED (The French Center for Population and Development) (1998). "Crisis and Demographic Transition in Africa." The CEPED NEWS, no. 2, pp. 1-5. Paris.

Chaudhury, R.H., Zaman, W. and Kari, Y. B. (2003). Impact of conflict on health including reproductive health in Nepal and Sri Lanka. Paper presented at the IUSSP Seminar on the Demography of Conflict and Violence, held in Oslo, Norway, 8-11 November 2003.

Cleland, J. (2001). "The effects of Improved survival on fertility: A reassessment." Population and Development Review, 27, Supplement: Global Fertility Transition, Pp. 60-92.

Cleland, J. and Wilson, C. (1987). "Demand theories of the fertility decline: An iconoclastic view." Population Studies, 41(1): 5-30.

Eloundou-Enyegue, P., Stokes, C.S., and Cornwell, G. T. (2000). "Are there crisis-led fertility declines? Evidence from central Cameroon." Population Research and Policy Review, 19: 47-72.

Fargues, P. (2000). "Protracted national conflict and fertility change: Palestinians and Israelis in the twentieth century." Population and Development Review, 26(3): 441-481.

Freedman, R., Xiao, X., Bohua, L., and Lavely, W.R. (1988). "Education and fertility in two Chinese provinces: 1967-70 to 1979-82." Asia Pacific Population Journal, 3(1): 3-29.

GSE (The Government of the State of Eritrea) and UNICEF (2001). Towards Realizing Child Rights in Eritrea: An Analysis of the Situation of Children and Women. Asmara 
Hill, K. (2004). "War, Humanitarian crisis, population displacement and fertility: A review of evidence": In Roundtable on the demography of forced migration. New York: Mailman School of Public Health Columbia University.

Hinde, P. A. and Mturi, A. J. (2000). "Recent trends in Tanzanian Fertility." Population Studies, 54: 177-191.

Hindin, M.J. (2000). "Women's autonomy, women's status and fertility-related behavior in Zimbabwe." Population Research and Policy Review, 19(3): 255283.

Hoem, J.M. (1991). "La standardisation indirecte améliorée et son application à la divortialité en Suède (1971-1989)." Population, 46: 1551-1568.

Hoem, J.M. (1993). "Classical demographic methods of analysis and modern eventhistory techniques." IUSSP: 22nd International Population Conference, Montreal, Canada, Volume 3: 281-291.

Holck, S.E. and Cates W. (1982). "Fertility and Population Dynamics in two Kampuchean Refugee Camps." Studies in Family Planning, 13(4): 118-124.

Innocent, N. (2001). Socio-economic factors associated with pre-marital childbearing and adolescents' age at first motherhood. Paper presented at the XXIV IUSSP General Population Conference, 18-24 August 2001. Salvador, Brazil.

Institute for Resource Development (IRD). 1990. An Assessment of DHS-I Data Quality. DHS Methodological Reports, No.1. Columbia, Maryland: IRD/Macro Systems, Inc.

Khlat, M., Deeb M., and Courbage, Y. 1997. "Fertility levels and differentials in Beirut during wartime: An indirect estimation based on maternity registers." Population Studies, 51(1): 85-92.

Knodel, J. and Pitaktepsombati, P. (1973). "Thailand: Fertility and Family Planning among rural and urban women.” Studies in Family Planning, 4(9): 229-255.

Lee, R.D. (1997). Population dynamics: Equilibrium, disequilibrium, and consequences of fluctuations. Handbook of Population and Family Economics. Vol. 1B, edited by Rosenzweig M.R. and Stark O. Amsterdam: Elsevier Science B.V.

Lesthaeghe, R. (1989). Social Organization, economic crisis, and the future of fertility control in Africa. In R. Lesthaeghe(ed.), Reproductive and Social Organization in sub-Saharan Africa. Berkeley, CA: University of California Press, 475-505. 
Lindstrom, D. P. and Berhanu, B. (1999). "The impact of war, famine, and economic decline on marital fertility in Ethiopia.” Demography, 36(2): 247-261.

Lindstrom, D.P. and Kiros, G. (2007). "The impact of infant and child death on subsequent fertility in Ethiopia." Population Research and Policy Review, 26(1): 31-49.

Luther, N.Y. and Pejaranonda, C. (1991). "The parity structure of fertility decline in Thailand, 1953-1979.” Genus, XLVII (1-2): 63-88.

Martin, T. and Juarez, F. (1995). "The impact of women's education on fertility in Latin America: Search for explanation." International Family Planning Perspective, 21(2): 52-57.

Martin, T. (1995). "Women's education and fertility: Results from 26 Demographic and Health Surveys." Studies in Family Planning, 26(4): 187-202.

Marwan, K., Pedersen, J.M., and Randall, S. (2003). The intifada, Palestinian fertility and education. Paper presented at the IUSSP seminar on the Demography of conflict and violence, held in Oslo, Norway, 8-11 November 2003.

Mason, K.O. (1993): "The impact of women's position on demographic changes during the course of development", in Federici N, Mason K.O. and Sogner S. (eds.), Women's Position and Demographic Change, Oxford, Clarendon Press, 19-42.

McGinn, T. (2000). "Reproductive health of war-affected populations: what do we know?" International Family Planning Perspectives, 26(4): 174-180.

Ministry of Education (2002). Eritrea: Essential Education Indicators 2001/02, pp. 139. Ministry of Education. Asmara, Eritrea.

Montgomery, M. R. and Casterline, J.B. 1998. Social networks and the diffusion of fertility control, Policy Research Division Working Paper no. 119. New York: Population Council.

Morgan, N. and Niraula, B. (1995) "Gender inequality and fertility in two Nepali villages." Population and Development Review, 21(3): 541-561.

Nair, S.N. (1996). "Determinants of birth intervals in Kerala: An application of Cox's hazard model." Genus, LII(3-4): 47-65.

NSEO (National Statistics and Evaluation Office) and ORC Macro (2003). Eritrea Demographic and Health Survey 2002. Calverton, Maryland, USA.

NSEO (National Statistics and Evaluation Office) and ORC Macro (1997). Eritrea Demographic and Health Survey 1995. Calverton, Maryland, USA. 
Njogu, W. and Martin, T. C. (1991). Fertility decline in Kenya: The role of training and spacing of births, in IRD/Macro International, Inc. 1991, Proceedings of the Demographic and Health Surveys World Conference Vol. III. Washington, D.C. 1991, Columbia, Maryland.

Palloni, A., Hill, K., and Pinto Aguirre, G. (1996). "Economic Swings and Demographic Changes in the History of Latin America." Population Studies, 50(1): 105-132.

Park, C. B., Ataharul, M., Chakraborty, N. and Kantner, A. (1998). "Partitioning the effect of infant and child death on subsequent fertility: An exploration in Bangladesh." Population Studies, 52(3): 345-356.

Peng, X.. (1987). "Demographic consequences of the Great leap forward in China's Provinces." Population and Development Review, 13: 639-670.

Rodriguez, G., Hobcraft, T., McDonald, J., Menken J., and Trussell, J. (1984). A comparative analysis of determinants of birth intervals. WFS Comparative Studies, 30. Voorburg, Netherlands: International Statistical Institute.

Rutenberg, N. and Diamond, I. (1993). "Fertility in Botswana: The recent decline and future prospects." Demography, 30(2): 143-157.

Santow, G. and Bracher, M.D. (1984). "Child death and time to the next birth in Central Java." Population Studies, 38(2), 241-253.

Sathar, Z., Crook, N., Callum, C., and Kazi, S. (1988). "Women's status and fertility change in Pakistan." Population and Development Review, 14(3): 415-432.

UN (1987). "Fertility Behaviour in the context of development: Evidence from the World Fertility Survey." Population Studies, 100 ST/ESA/SERA/100.

UN (2002). United Nations Development Assistance Framework (UNDAF) (20022006). Asmara, Eritrea

Watkins, S. and Menken, J. (1985). "Famines in historical perspective." Population and Development Review, 11(4): 647-675.

Yang, Q. (1990). "Age at first marriage and fertility in rural Anhui, china." Journal of Biosocial Science, 22(2): 143-157.

Yavuz, S. (2006). "Completing the fertility transition: Third birth developments by language groups in Turkey." Demographic Research, 15(15): 435-460. 
Woldemicael: Recent fertility decline in Eritrea

\section{Annex}

Table 8: List of variables used in the analysis of fertility together with the percentage distribution of births in each category

\begin{tabular}{|c|c|c|}
\hline \multicolumn{3}{|c|}{ Percentage in Category } \\
\hline Variable & First births & Higher order births \\
\hline \multicolumn{3}{|c|}{ Calendar period } \\
\hline$<1990$ & 38.5 & 29.8 \\
\hline $1990-92$ & 14.3 & 15.6 \\
\hline $1993-95$ & 18.7 & 19.2 \\
\hline $1996-98$ & 15.6 & 19.0 \\
\hline 1999-01 & 12.9 & 16.4 \\
\hline \multicolumn{3}{|c|}{ Age of mother at previous birth } \\
\hline$<20$ & 47.2 & 15.6 \\
\hline $20-24$ & 36.0 & 30.3 \\
\hline $25-29$ & 12.9 & 26.9 \\
\hline $30-34$ & 3.1 & 18.1 \\
\hline $35-39$ & 0.6 & 7.4 \\
\hline $40-49$ & 0.1 & 1.7 \\
\hline \multicolumn{3}{|c|}{ Birth order } \\
\hline $2-3$ & - & 47.0 \\
\hline $4-5$ & - & 29.6 \\
\hline $6-7$ & - & 15.5 \\
\hline $8+$ & - & 7.9 \\
\hline \multicolumn{3}{|c|}{ Previous birth interval } \\
\hline$<18$ & - & 22.7 \\
\hline $18-23$ & - & 18.0 \\
\hline $24-35$ & - & 31.1 \\
\hline $36-47$ & - & 13.2 \\
\hline $48+$ & - & 15.0 \\
\hline \multicolumn{3}{|c|}{ Survival of preceding child } \\
\hline Alive & - & 92.6 \\
\hline Dead & - & 7.4 \\
\hline \multicolumn{3}{|c|}{ Age at $1^{\text {st }}$ marriage } \\
\hline$<16$ & 35.3 & 39.8 \\
\hline $16-19$ & 36.4 & 34.3 \\
\hline $20+$ & 28.3 & 25.9 \\
\hline
\end{tabular}


Table 8: (continued)

\begin{tabular}{lcc}
\hline Percentage in Category & & \\
\hline Variable & First births & Higher order births \\
\hline Childhood residence & 79.0 & 90.6 \\
Rural & 21.0 & 9.4 \\
Urban & & \\
Mother's education & 70.0 & 80.1 \\
No education & 20.9 & 15.7 \\
Primary & 9.1 & 4.2 \\
Secondary and higher & & \\
Region & 17.1 & 16.2 \\
Southern Red Sea & 12.5 & 10.6 \\
Central & 17.0 & 17.4 \\
Northern Red Sea & 16.9 & 18.1 \\
Anseba & 16.8 & 17.0 \\
Gash Barka & 19.7 & 20.8 \\
Southern & 5,931 & 17,531 \\
Total & & \\
\hline
\end{tabular}


Woldemicael: Recent fertility decline in Eritrea 